\title{
Assessment of Failure and Repair Behaviors of the Jebba Hydroelectric Power Station
}

\author{
Cornelius Temitope Thomas ${ }^{1 *}$, Olalekan Ogunbiyi ${ }^{2}$, Mudathir Funsho Akorede ${ }^{2}$ and Benjamin Jimi \\ Olufeagba $^{2}$
}

${ }^{1}$ Department of Electrical and Information Engineering, Achievers University, P.M.B.1030, Owo, Nigeria.

${ }^{2}$ Department of Electrical and Electronics Engineering, University of Ilorin, P.M.B. 1515, Ilorin, Nigeria.

*Corresponding author: thomasct@achievers.edu.ng, Tel: +234(0)8051739342

\begin{abstract}
Nigeria power generation is circa $4000 \mathrm{MW}$ as at October 2016, this is far less than the national required value. Jebba Hydroelectric Power Station (JHEPS) is one of the three major hydropower stations in the country which its maximum average generation value is still less than the rated value of 578.4 MW. This paper presented some basic concepts of analysis of failure and repair. An algorithm was set up to extract the contiguous set of up-times and down-times to determine time-tofail (TTF) and time-to-repair (TTR) events, these events were analyzed for stochastic study. It was observed that the longest up time was 262 days and seen in turbo-alternator unit five, while the shortest was zero day and seen in the entire units except that of unit two. The longest downtime was 133 days and seen in the turbo-alternator of unit one, the least time-to-repair is a day and common to all the units. The frequency distributions for both TTF and TTR showed that 79\% of TTF events and 57\% of TTR events are distributed in the first 2 classes
\end{abstract}

Keywords: Contiguous state, Data sample, Up and Down-times, Turbo-alternator and Time-to-fail/repair

(C) 2018 Penerbit UTM Press. All rights reserved

Article History: received 23 August 2018; accepted 16 December 2018; published 26 December 2018

\section{INTRODUCTION}

The level of the development of a society is greatly influenced by adequate generation and efficient distribution of electricity. It is in this light that this paper presents the study of one of the major hydropower stations in Nigeria - the Jebba Hydroelectric Power Station.

Nigeria is a country with a population of about $180,000,000$ and the most populous in Africa. As at August 2010, Nigeria had a population of about $150,000,000$ people and the peak generation attained by the Power Holding Company of Nigeria (PHCN) was 3,804 MW. Compared to South Africa, a nation well on its way to being in the class of top 20 economies, with a population of 50,000,000 people has a grid-based generating capacity of 40,000 MW [1]. Nigeria's population has rapidly increased to 180 million and it is expected to reach 230 million by the year 2030, its electricity generation is still less than $4000 \mathrm{MW}$ [2], although, a peak generation of 5074.7 MW was recorded as at October 2016 but only lasted for a few days [2].

JHEPS is built around a dam located on the river Niger, about 64 miles due south of a much larger dam - the Kainji and approximately $350 \mathrm{~km}$ away from Lagos, Nigeria. It was built between 1981 and 1983, operation commenced in 1984, although official commissioning took place on April 13, 1985. It has six Kaplan reaction-type turbines, each using a five-bladed runner directly coupled to compatible alternators to give turbo-alternators $[3,4]$ rated at 96.4 MW and operating at a synchronous speed of 93.75 rpm [5] with a head of 27.6 metres and a fast flow rate of $380 \mathrm{~m} 3 / \mathrm{s}$. The dam with a live storage capacity of about $1,000,000,000.0 \mathrm{~m} 3$ is constructed from zoned earth and rockfill materials and has a crest elevation of $108.0 \mathrm{~m}$, when operating normally; the water level is about $99.0 \mathrm{~m}$ $[4,5]$. It has a spillway capable of discharging up to $13,600 \mathrm{~m} 3 / \mathrm{s}$ under normal operating conditions and $16,400 \mathrm{~m} 3 / \mathrm{s}$ at both $106.0 \mathrm{~m}$ elevation and emergency spillway levels. Each unit has an alternator that is linked to the turbine via a vertical shaft and generates at $16 \mathrm{kV}, 50 \mathrm{~Hz}$ with a nominal power factor of 0.85 . The electrical output from each unit is directly coupled to a compatible step-up transformer designed to produce $330 \mathrm{kV}$ from the generated $16 \mathrm{kV}$. Numerous accessories are included to ease matters of maintenance including cranes and other relevant equipment $[3,4,5]$.

\section{CONCEPT OF FAILURE AND REPAIR}

Failure of an engineering system is an event after which the system is incapacitated to perform its purpose. Product like bulb once failed cannot be repaired, therefore, repair is only applicable to a system which does not fail ones, and an example of such is a turbo-alternator which can undergo several repairs [6]. Turbo-alternator as a single system has no redundancy built in it and hence has its operational status as either functioning or not, that is, it has 'up' 
(functioning) or 'down' (breakdown) states as shown in Figure 1.

The state diagram is as shown in Figure 2, since there are two states, there are $2^{\wedge} 2$ (four) possible transitions between the two states, 0 to 0,0 to 1,1 to 0 and 1 to 1 , this are also illustrated in Figure 2. $\lambda$ is the hazard or failure rate, while $\mu$ is the repair rate. From Figure 2, the period of time from a repair time to a breakdown (a functional period without a breakdown, a single up time) is known as timeto-fail (TTF), [7]. In contrast, the period of a single down time is known as time-to-repair (TTR), [8].

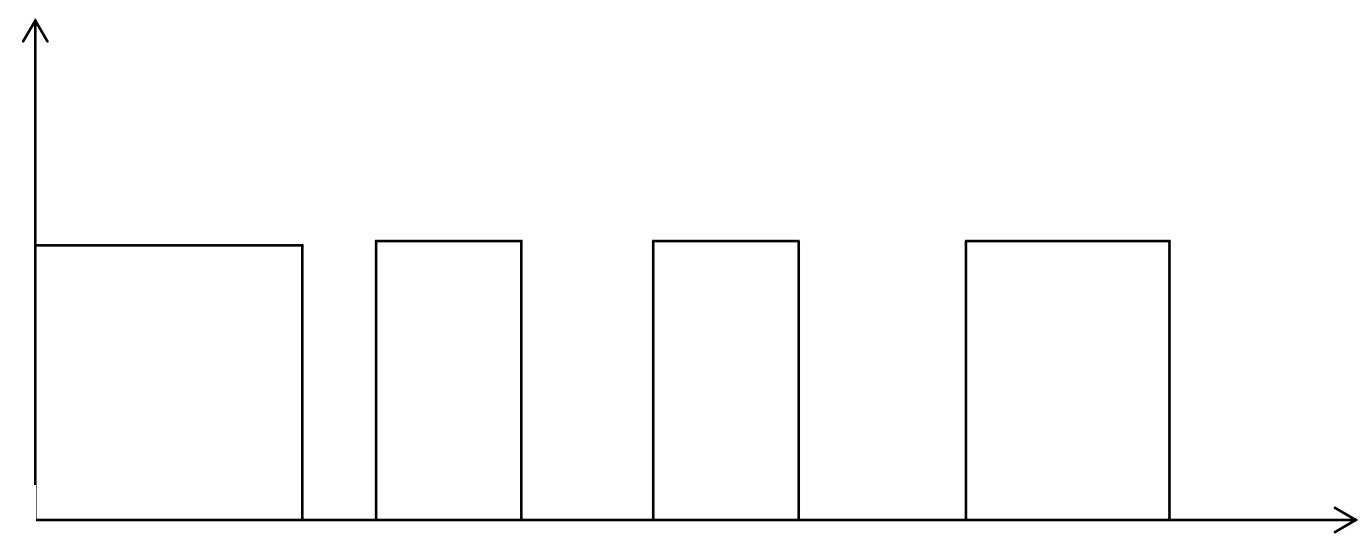

Figure 1. Time diagram of a two-state system

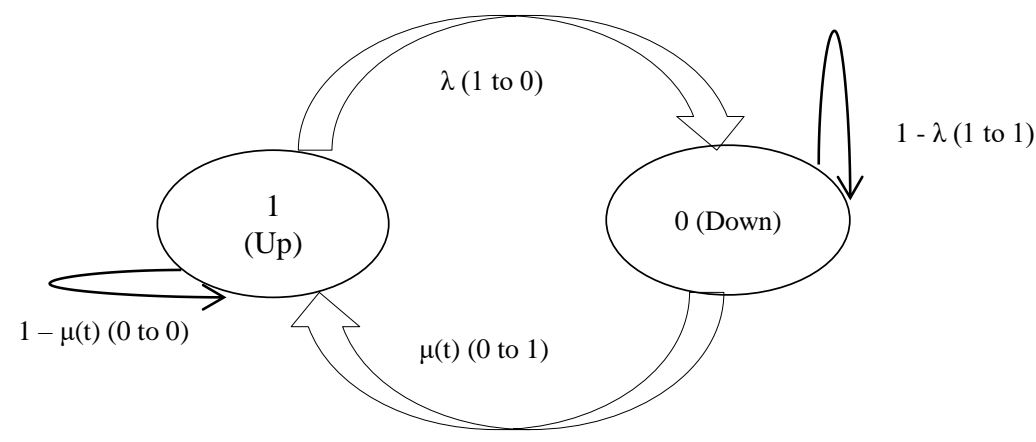

Figure 2. State diagram of a two-state system

\section{EXTRACTION OF TIME-TO-FAIL AND TIME- TO-REPAIR}

In order to study the stochastic process representing the time -to -fail of a unit, assume that $\mathrm{T}_{\mathrm{up} 1, \mathrm{k}}$ is the time at the start of an 'up' period, $\mathrm{k}$, and $\mathrm{T}_{\mathrm{up} 2, \mathrm{k}}$ is the time when the unit fails. Then the duration of the $\mathrm{kth}$ running period designated as $t_{u p, k}{ }^{j}$ for the $j$-th unit satisfies the expression:

$$
\mathrm{t}_{\mathrm{up}, \mathrm{k}}{ }^{\mathrm{j}}=\mathrm{T}_{\mathrm{up} 2, \mathrm{k}}^{\mathrm{j}}-\mathrm{T}_{\mathrm{up} 1, \mathrm{k}}^{\mathrm{j}}
$$

In order to generate the sequence of time-to-fail, an algorithm shown below was realized. It involves generating a variable that is zero if a unit is non-functional due to breakdown or servicing and 1 when operational. This definition may experience problems in instances where units work for part of a day. In this work, units that are not available for the full day were assumed to have failed.

Let $\mathrm{P}_{\mathrm{ji}}$ be the output energy for $\mathrm{TA}_{\mathrm{j}}$ on day $\mathrm{i}$ in the database, then the auxiliary sequence for daily condition of the $T A_{j}$ satisfies:

$$
\begin{aligned}
\mathrm{W}_{\mathrm{ji}} & =0, \text { if } \mathrm{P}_{\mathrm{ji}}<0, \\
& =1 \text { if } \mathrm{P}_{\mathrm{ji}}>0, \text { for } \mathrm{i}=1,2, \ldots, 3652 \text { [i.e. } 10 \text { years] }
\end{aligned}
$$

The set $\left\{\mathrm{w}_{\mathrm{ji}}\right\}$ contains all the information about the condition of the units over the given period. An algorithm was designed to determine the number of working days for each set of contiguous 'ones'. It employs a number of variables internally for enabling the count and was realized as shown in the flowchart in Figure 3.

$$
\begin{aligned}
& \text { O/P - Output } \\
& \text { j } \quad \text { Turbo-Alternator index } \\
& \mathrm{i} \quad \text { - Day index } \\
& \mathrm{k} \quad \text { - Event counter }
\end{aligned}
$$

The study of failures of unit $\mathrm{j}$ is the study of the distribution of the spell of up - times or time - to - fail for the unit. The sequence of time-to-fail for each TA over the can be expressed as follows:

$$
\mathrm{X}^{\mathrm{j}}=\left\{\mathrm{t}_{\text {up }, \mathrm{k}^{\mathrm{j}}}: \mathrm{k}=1,2, \ldots . . \mathrm{N}_{\text {up }}^{\mathrm{j}}\right\}
$$

where, $\mathrm{N}_{\text {up }}^{\mathrm{i}}$ is the total number of 'Up-times' for the $\mathrm{j}$-th TA

A stochastic approach was applied to study the distribution failure satisfied by the sample, $X{ }^{j}$. Sturges' rule was adopted to determine the intervals and exploit both basic and internal functions to extract the frequencies of occurrence of each interval [9]. 
The steps of the algorithm are as follows:

Step 1: Generate the sequence $\mathrm{X}^{\mathrm{j}}$;

Step 2: Determine the Interval size;

Step 3: Generate the frequency distribution over the range; and

step 4: Study the Histogram.

$$
\begin{aligned}
& u=1+3.3 \log N \\
& c=\max [A]-\min [A]
\end{aligned}
$$

where:

$\mathrm{u}$ - is the number of class intervals;

$\mathrm{N}$ - number of samples available;

A - the set in view, which may be either the sequence of time-to-fail or time-to-repair;

$\mathrm{c}$ - the class width

A class is a set of data that belong to the same group and may be viewed to have similar behaviours, hence stand as a single entity. A class maybe viewed as a 'single event'. The Frequency function of EXCEL-VBA was used for grouping of the failure and repair events.
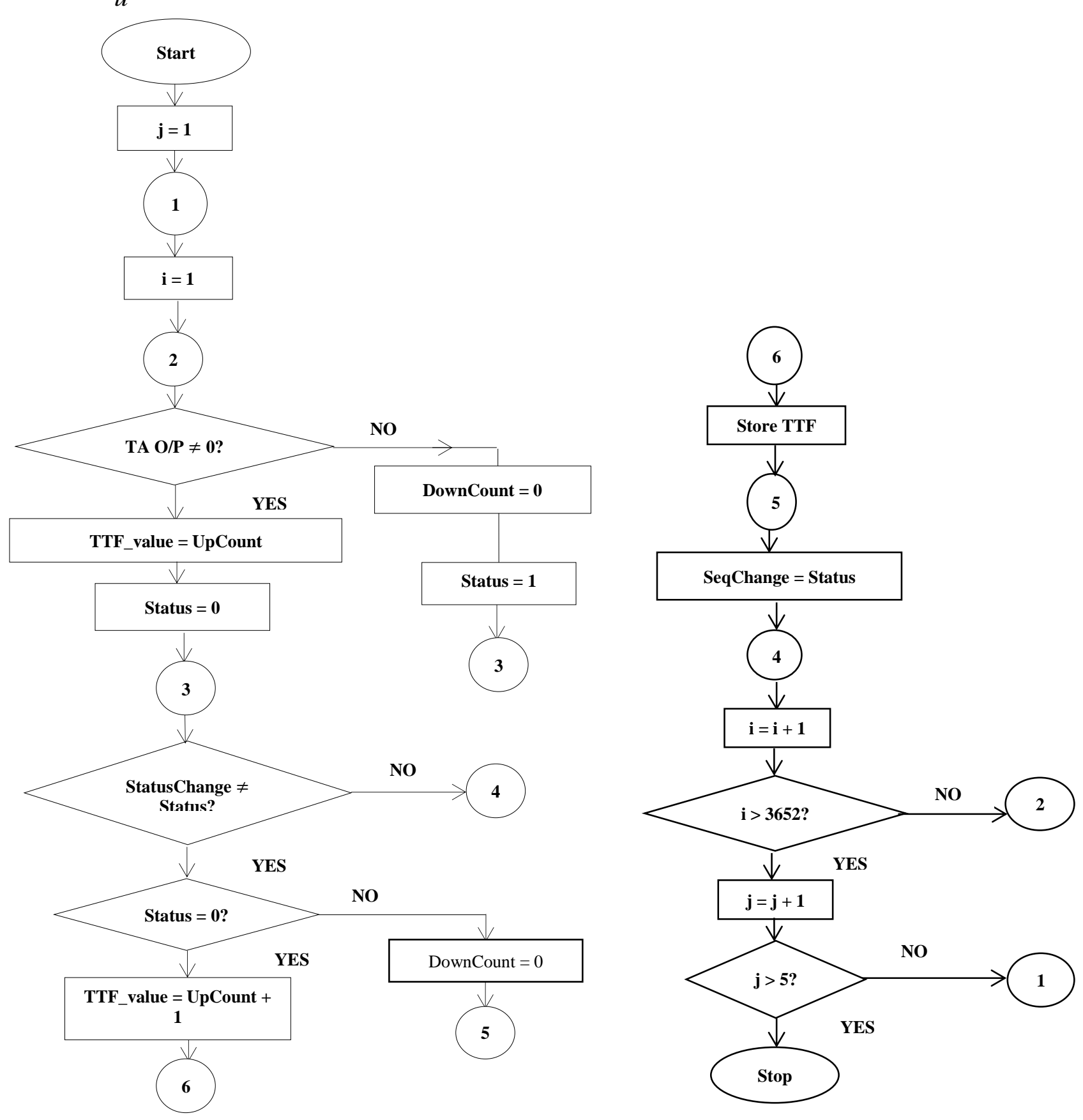

Figure 3. Flowchart for extraction of TTF for TA units 1 to 5. 


\section{RESULTS AND DISCUSSION}

The outcome of the flow chart of Figure 1 is as shown in Table 1, unit 1 recorded the least events for both failures and repairs, it has 88 breakdowns and 87 repairs within a period of 10 years (2005 to 2014), and this is closely followed by unit 2 . TA2 recorded the highest number of events, it has 151 failures and 150 repairs events. It was observed that all the TAs except that of unit 4 had their numbers of TTF a unity higher than that of TTR, this implies that such TAs are working as at the end of data computation.

\subsection{Time-to-fail Events}

The Frequency Distribution of TTF of each unit is shown in Table 2, "data" is the value (in days) of the TTF values while " $\mathrm{f}$ " is the number of event within a range of data. The width of the class for each TA unit differs because the number of events are not uniform for all the units. From Table 2, it can be seen that the first class possesses the highest number of data in all the units. The histogram of TTR of each unit are presented in Figure 4. In all the cases, the histograms seem to portray a process that I maximum at the start and tapers off with time. Nonetheless caution must be taken because some of the histograms manifest behavior indicative of possibly more than one process

\subsection{Time-to-repair Events}

The Frequency Distribution of TTR of each unit is shown in Table 3, all the TA has the longest TTR in the first group which is an indicative of good repair culture as short times are spent in repairing the TAs. A good repair characteristic can be said to be that that has most of its TTR in the earlier groups. Table 3 shows the repair distribution of the JHEPS, most of the repair events are distributed to the least classes of the group. The Histograms are presented in Figure 5.

Table 1. Summary of TTF and TTR

\begin{tabular}{|c|c|c|c|c|c|c|}
\hline $\begin{array}{c}\text { TA } \\
\text { Unit }\end{array}$ & $\begin{array}{c}\text { Number of } \\
\text { TTF Events }\end{array}$ & $\begin{array}{c}\text { Minimum TTF } \\
\text { [Days] }\end{array}$ & $\begin{array}{c}\text { Maximum TTF } \\
\text { [Days] }\end{array}$ & $\begin{array}{c}\text { Number of TTR } \\
\text { Events [Days] }\end{array}$ & $\begin{array}{c}\text { Minimum TTR } \\
\text { [Days] }\end{array}$ & $\begin{array}{c}\text { Maximum TTR } \\
\text { [Days] }\end{array}$ \\
\hline 1 & 88 & 0 & 209 & 87 & 0 & 133 \\
\hline 2 & 151 & 1 & 226 & 150 & 0 & 39 \\
\hline 3 & 91 & 0 & 231 & 90 & 0 & 47 \\
\hline 4 & 130 & 0 & 123 & 130 & 0 & 124 \\
\hline 5 & 125 & 0 & 262 & 124 & 0 & 44 \\
\hline
\end{tabular}

Table 2. Grouped data of histogram of Time-to-fail

\begin{tabular}{|c|c|c|c|c|c|c|c|c|c|c|}
\hline \multirow{2}{*}{ Class } & \multicolumn{2}{|c|}{ TA Unit 1 } & \multicolumn{2}{|c|}{ TA Unit 2 } & \multicolumn{2}{c|}{ TA Unit 3 } & \multicolumn{2}{c|}{ TA Unit 4 } & \multicolumn{2}{c|}{ TA Unit 5 } \\
\cline { 2 - 11 } & Data & f & Data & f & Data & F & Data & f & Data & F \\
\hline 1 & $1-22$ & 38 & $1-22$ & 128 & $1-25$ & 52 & $\mathbf{1 -} \mathbf{1 4}$ & 87 & $1-30$ & 96 \\
\hline 2 & $23-44$ & 35 & $22-46$ & 14 & $26-50$ & 23 & $15-28$ & 26 & $31-60$ & 25 \\
\hline 3 & $45-66$ & 6 & $47-69$ & 1 & $51-75$ & 5 & $27-42$ & 10 & $61-90$ & 1 \\
\hline 4 & $67-88$ & 0 & $70-92$ & 4 & $76-100$ & 3 & $43-56$ & 4 & $91-120$ & 0 \\
\hline 5 & $89-110$ & 4 & $93-115$ & 2 & $101-125$ & 1 & $57-70$ & 1 & $121-150$ & 1 \\
\hline 6 & $111-132$ & 2 & $116-138$ & 1 & $126-150$ & 5 & $71-84$ & 0 & $151-180$ & 0 \\
\hline 7 & $133-154$ & 2 & $139-161$ & 0 & $151-175$ & 1 & $85-98$ & 0 & $181-210$ & 0 \\
\hline 8 & $155-176$ & 0 & $162-184$ & 0 & $176-200$ & 0 & 1 & 1 & $211-240$ & 0 \\
\hline 9 & 177 & 1 & $185-207$ & 0 & 201 & 1 & 113 & 1 & 241 & 2 \\
\hline 10 & & & 298 & 1 & & & & & & \\
\hline
\end{tabular}

Table 3. Grouped data of histogram distribution of TTR

\begin{tabular}{|c|c|c|c|c|c|c|c|c|c|c|}
\hline Class & \multicolumn{2}{|c|}{ TA Unit 1 } & \multicolumn{2}{|c|}{ TA Unit 2 } & \multicolumn{2}{c|}{ TA Unit 3 } & \multicolumn{2}{|c|}{ TA Unit 4 } & \multicolumn{2}{c|}{ TA Unit 5 } \\
\hline & Data & f & Data & F & Data & f & Data & f & Data & F \\
\hline 1 & $1-16$ & 70 & $1-3$ & 67 & $\mathbf{1 - ~ 5}$ & 63 & $1-14$ & 87 & $1-5$ & 71 \\
\hline 2 & $17-32$ & 13 & $4-6$ & 19 & $6-10$ & 9 & $15-28$ & 17 & $6-10$ & 25 \\
\hline 3 & $33-48$ & 1 & $7-9$ & 8 & $11-15$ & 2 & $29-42$ & 15 & $11-15$ & 13 \\
\hline 4 & $49-64$ & 1 & $10-12$ & 5 & $16-20$ & 2 & $43-56$ & 4 & $16-20$ & 5 \\
\hline 5 & $55-80$ & 1 & $13-15$ & 14 & $21-25$ & 3 & $57-70$ & 6 & $21-25$ & 5 \\
\hline 6 & $81-96$ & 0 & $16-18$ & 11 & $26-30$ & 6 & $71-84$ & 0 & $24-30$ & 1 \\
\hline 7 & $97-112$ & 0 & $19-21$ & 12 & $31-35$ & 2 & $85-98$ & 0 & $31-35$ & 2 \\
\hline 8 & $113-128$ & 0 & $22-24$ & 4 & $36-40$ & 2 & $99-112$ & 0 & $36-40$ & 1 \\
\hline 9 & 129 & 1 & $23-27$ & 4 & 41 & 1 & 113 & 1 & 41 & 1 \\
\hline 10 & & & & 6 & & & & & & \\
\hline
\end{tabular}


TTF for TA $1(2005-2014)$

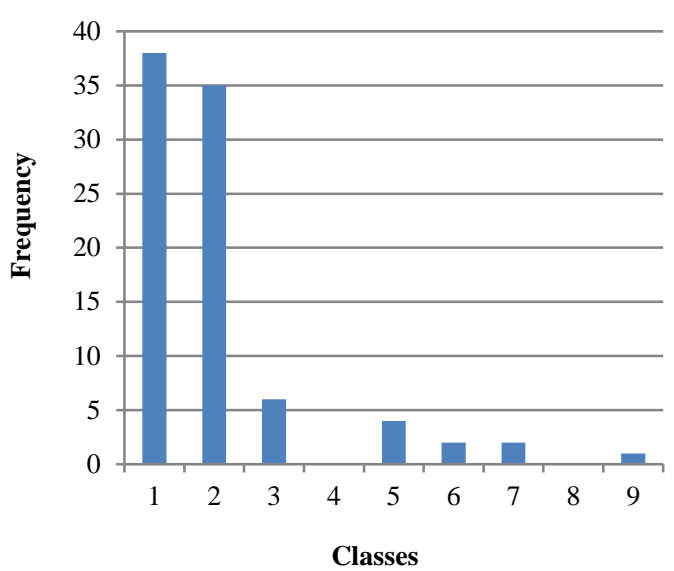

Figure 4a. Turbo-alternator 1

TTF for TA $2(2005-2014)$

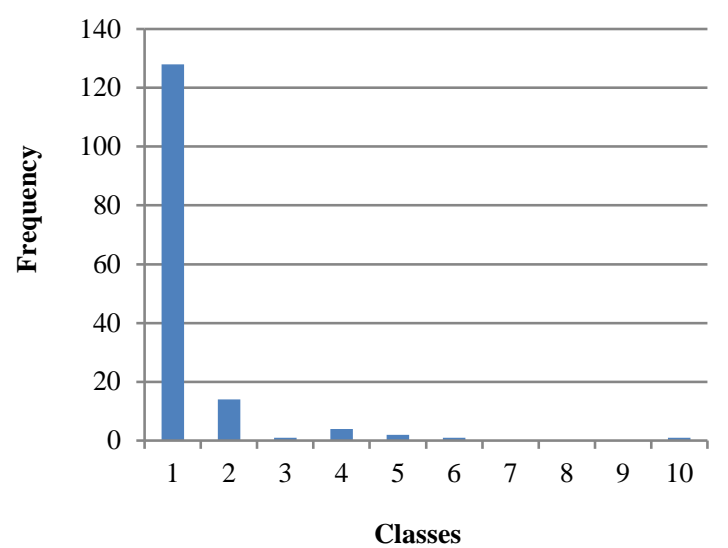

Figure 4b. Turbo-alternator 2

TTF for TA 3 (2005 - 2014)

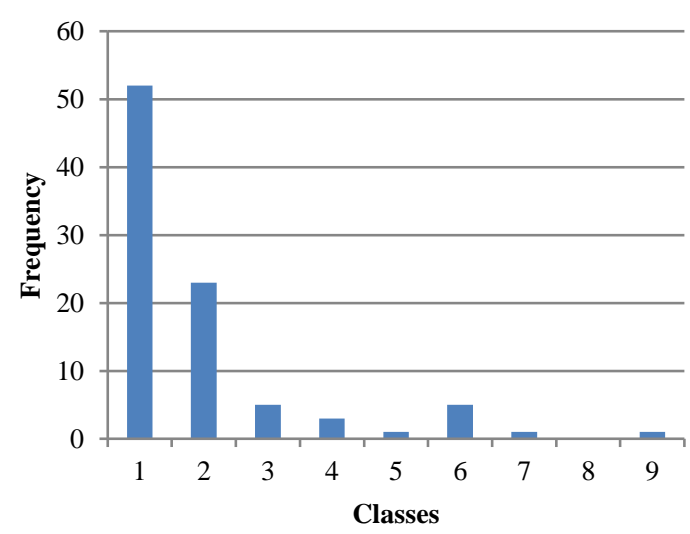

Figure 4c. Turbo-alternator 4
TTF for TA $4(2005$ - 2014)

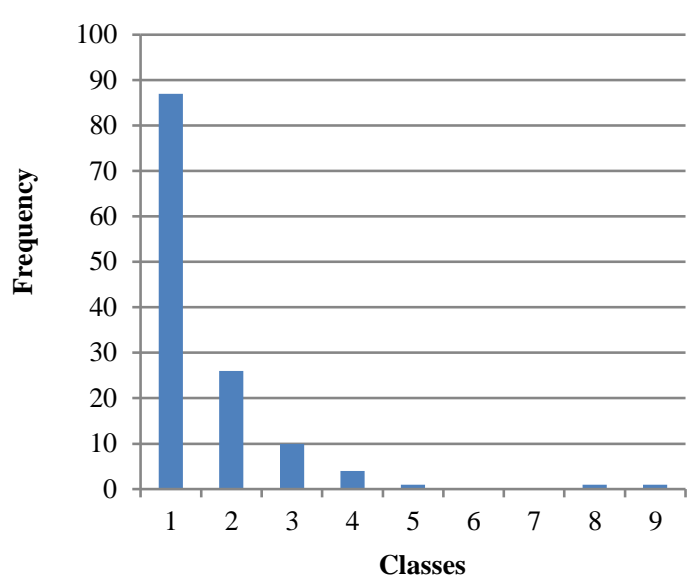

Figure 4d. Turbo-alternator 4

TTF for TA 5 (2005 - 2014)

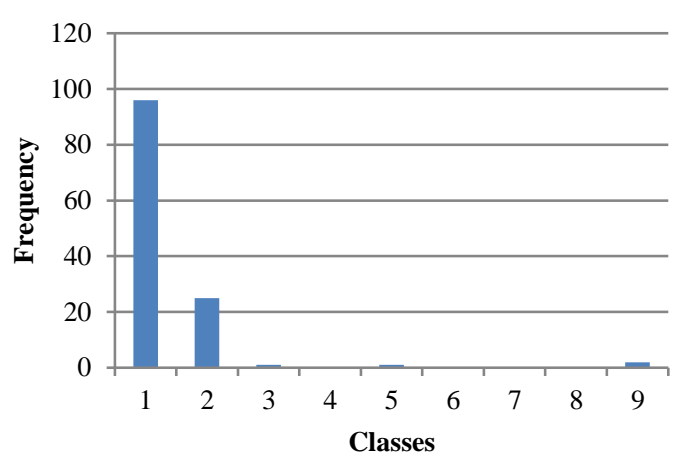

Figure 4e. Turbo-alternator 5

Figure 4. TTF histogram for unit 1 to $5(2005-2014)$

TTR for TA $1(2005-2014)$

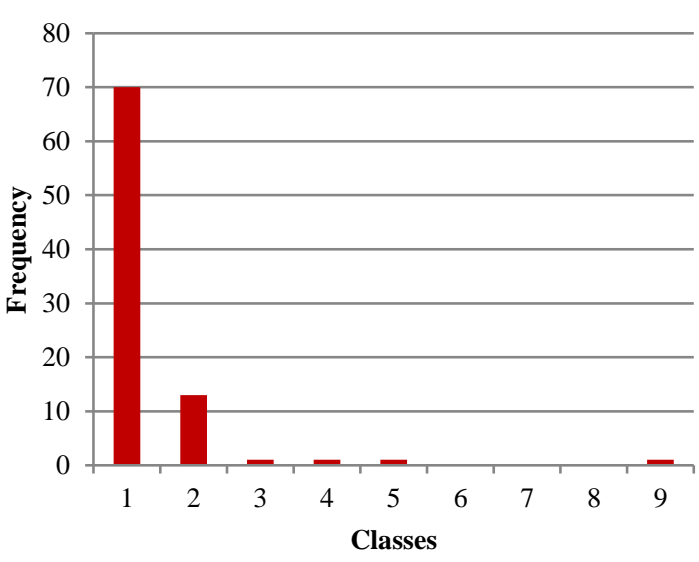

Figure 5a. Turbo-alternator 1 
TTR for TA 2 (2005 - 2014)

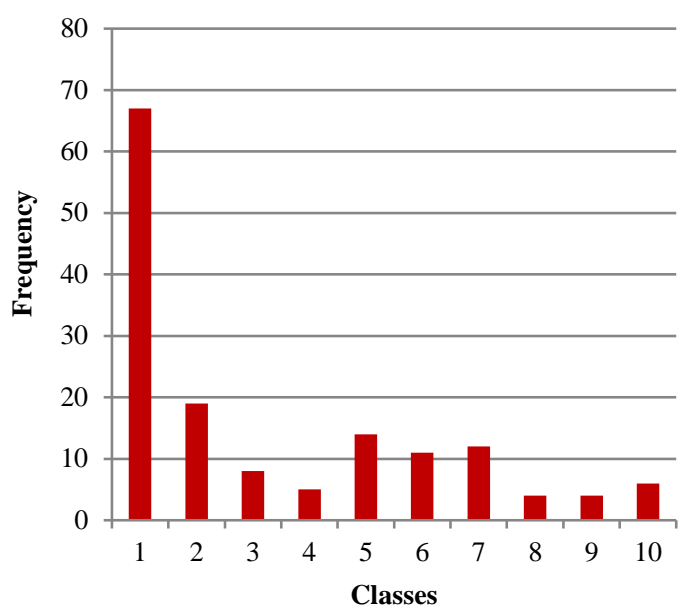

Figure 5b.Turbo-alternator 2

TTR for TA 3 (2005 - 2014)

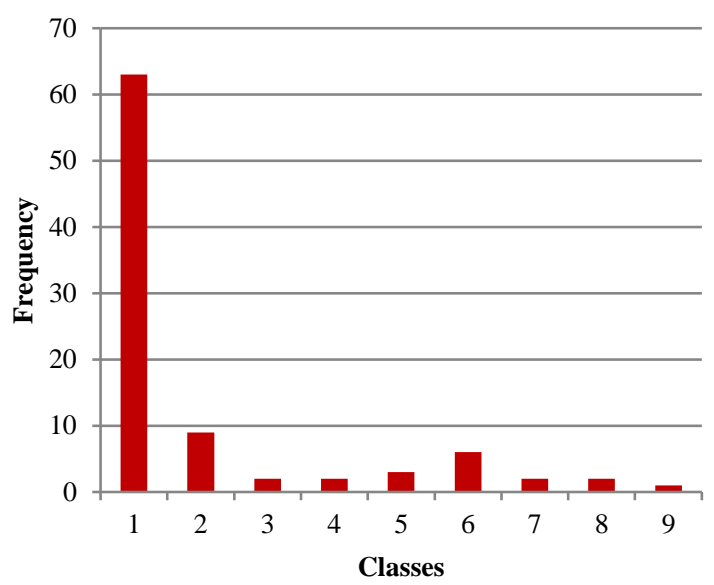

Figure 5c. Turbo-alternator 3

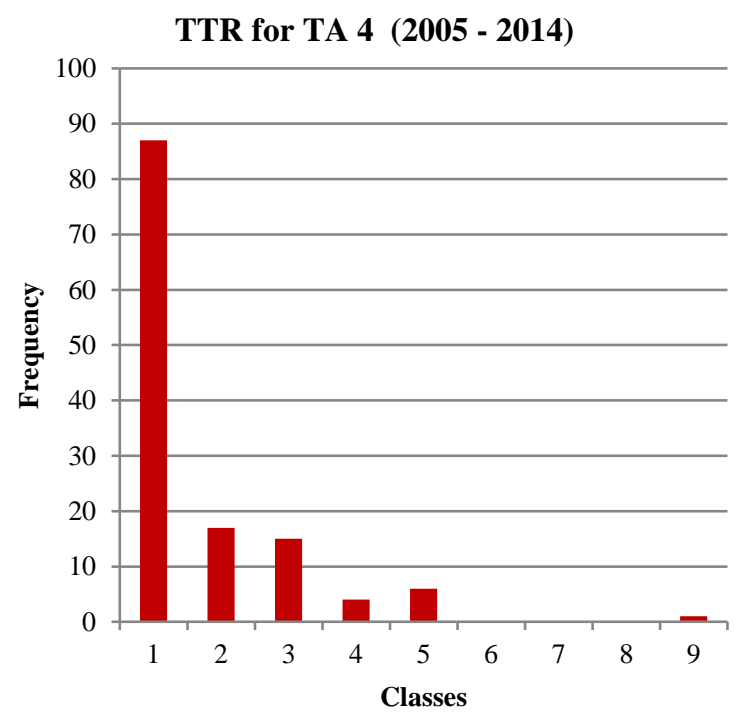

Figure 5d. Turbo-alternator 4
TTR for TA 5 (2005 - 2014)

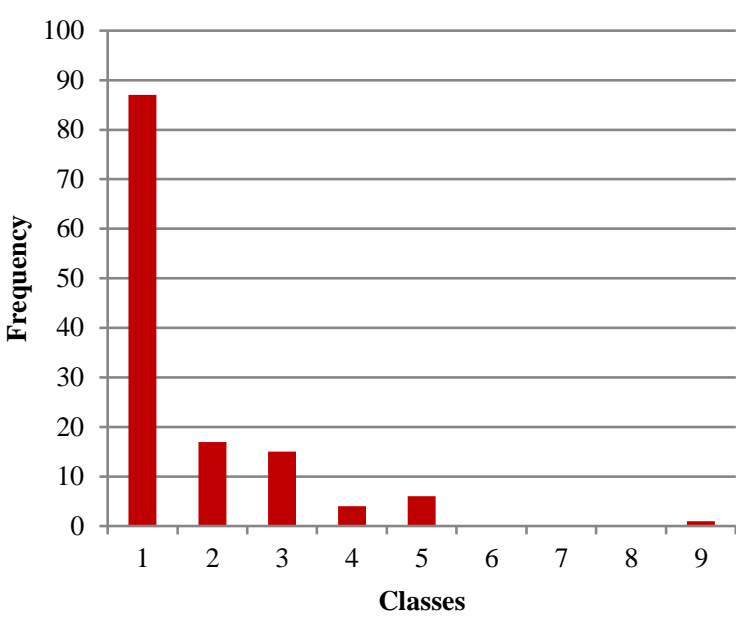

Figure 5e. Turbo-alternator 5

Figure 5: TTR histogram for unit 1 to 5 (2005 - 2014)

\section{CONCLUSION AND RECOMMENDATION}

All the TA unit of the station has most of their TTF distribution in the earlier frequency group, this shows that there are more short times to breakdown than long times which is a bad behaviour. The maximum up-time recorded during this period is 262 days (approximately 9 months) as seen in TA5, however this unit did not show a good failure behaviour when observed over the entire period in consideration, unit 4 has the least maximum up-time of a value of 123 days.

Unit 2 showed the least maximum breakdown duration of 39 days, while the longest TTR was seen in unit 1, a value of 133 days. Below are some recommendations for better performance of the station.

The failure record should be recorded in hourly basis rather than the daily basis in practice, this will aid accuracy and precision.

The nature of failures should be indicated, either failure in the alternator, turbine and even shutdowns due to maintenance purpose should be clearly stated. This will also help the maintenance department and the management to identify the spares to cater for the most to aid fast repairs and good economy policy.

\section{REFERENCES}

[1] "Roadmap for Power Sector Reform (A Customerdriven Sector-wide Plan to Achieve Stable Power Supply)" by Presidential Action Committee on Power Delivered in Lagos, Nigeria, on 26 August, 2010.

[2] "Modelling and Optimal Control of the Cascaded Kainji and Jebba Hydroelectric Power System", $\mathrm{Ph} . D$. seminar, Faculty of Engineering, University of Ilorin, Nigeria, 12 October, 2016

[3] C. T. Thomas, M. F. Akorede, O. Ogunbiyi, B. J. Olufeagba, J. S. Samuel, "A Study of Energy Conversion at the Jebba Hydroelectric Power Station", 2017 IEEE 3rd International Conference on Electro-Technology for National Development 
(NIGERCON), IEEE, (2017), ISSN: 2377-2697, pp. 828-833

[4] O. Ogunbiyi, "Energy generation" Jebba Hydro Electric Plc, retrieved from http://jebba hydroelectric.weebly.com/index.html on 9 January, 2015.

[5] "Jebba Hydroelectric Power Station, 578, 400kW", a pamphlet drafted by Jebba Hydroelectric Power Station, Jebba, Niger State.

[6] A. Abdulkarim, S. M. Abdelkader, and D. J. Morow, "Reliability importance measures of concepts for standalone hybrid renewable energy microgrid" in ENEFM, Oludeniz, 2014

[7] P. D. T. O'Conor, Practical Reliability Engineering, Heyden \& Son Ltd, 1981. ISBN: 0-85501-496-2.

[8] Y. A. Adediran, Introduction to Reliability Engineering, First Edition, FINOM Associates, Nigeria, 2014, ISBN: 978-52341-2-1

[9] C. E. Ebeling, "An Introduction to Reliability \& Maintainability Engineering", McGraw-Hill Companies, 1996, ISBN: 0070188521, p. 359. 